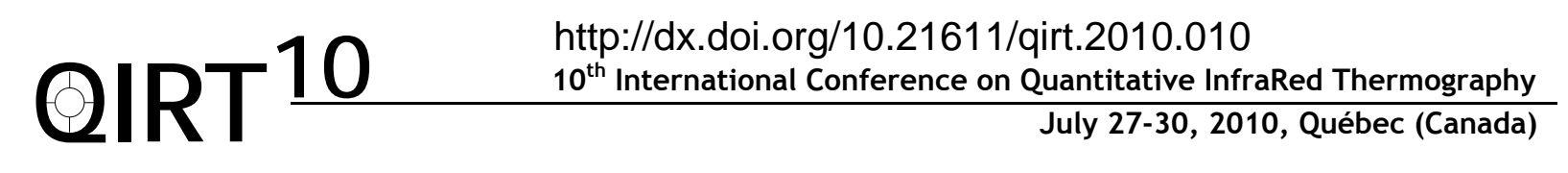

\title{
Analysis of the possibility of defect determination using cold excitation in thermal tomography
}

by M. Bajorek*, A. Nowakowski*

*Department of Biomedical Engineering, Gdansk University of Technology, Poland, martom@biomed.eti.pg.gda.pl

\begin{abstract}
The main aim of this work was to analyze the possibilities of reconstructing object parameters using thermal tomography approach. Cooling excitation by the stream of carbon dioxide of different duration was applied using a cryogenic instrument. First, based on the results of numerical simulation of a tested structure, the thermal contrast was calculated for different depths of defect location. In the next step, experiments on phantoms with different defects inserted were performed. Determination of defects was proved to be possible using the reconstruction procedure of thermal tomography. Conditions necessary for reliable reconstruction of different defects were analysed.
\end{abstract}

\section{Introduction}

In nondestructive testing of materials, not only defect detection but also characterization of defect properties, it's size and depth, are important [1]. In this aspect, thermal tomography procedure (TT) can be considered as a method which allows identification of a defect at a particular sample layer [2, 3, 4]. Probably Vavilov was the first who proposed the term Thermal Tomography [3]. The original idea was to slice thermally a specimen in depth [3,4]. In practice it is a "pseudo-tomography" as the proposed procedure is performed assuming only one-dimensional heat transfer. Analysis is based on the observation that the time of maximum thermal contrast is proportional to the square of the depth of a thermal defect. Using this concept he was dealing with thermal non-destructive testing (TNDT) of mechanical structures. Though the first publications on TT procedure have been published more than 20 years ago this method may be regarded as being still in the early development stage, especially taking into account the limited number of practical applications published up to now.

The concept of material testing by active dynamic thermography (ADT) is based on delivery of some energy to a tested specimen and observation of thermal transients at it's surface as the response [5]. Typically characterization of a tested object is possible by determination of thermal time constants, which values strongly correlate to the internal structure of a tested object. Using the same measurement data another approach is to apply the procedure of thermal tomography (TT). In TT the structure of a tested object is determined based on ADT experimental results and comparison of measurement data with simulation of this experiment. We propose thermal tomographic visualization of 3-D structures [5, 6] by solving the inverse problem which finds distribution of thermal conductivity inside the bulk of a tested object. The full algorithm of thermal tomography consists of several steps, which are presented on Fig. 1. Identification and use of a proper model of the tested structure is the most important element of this procedure.

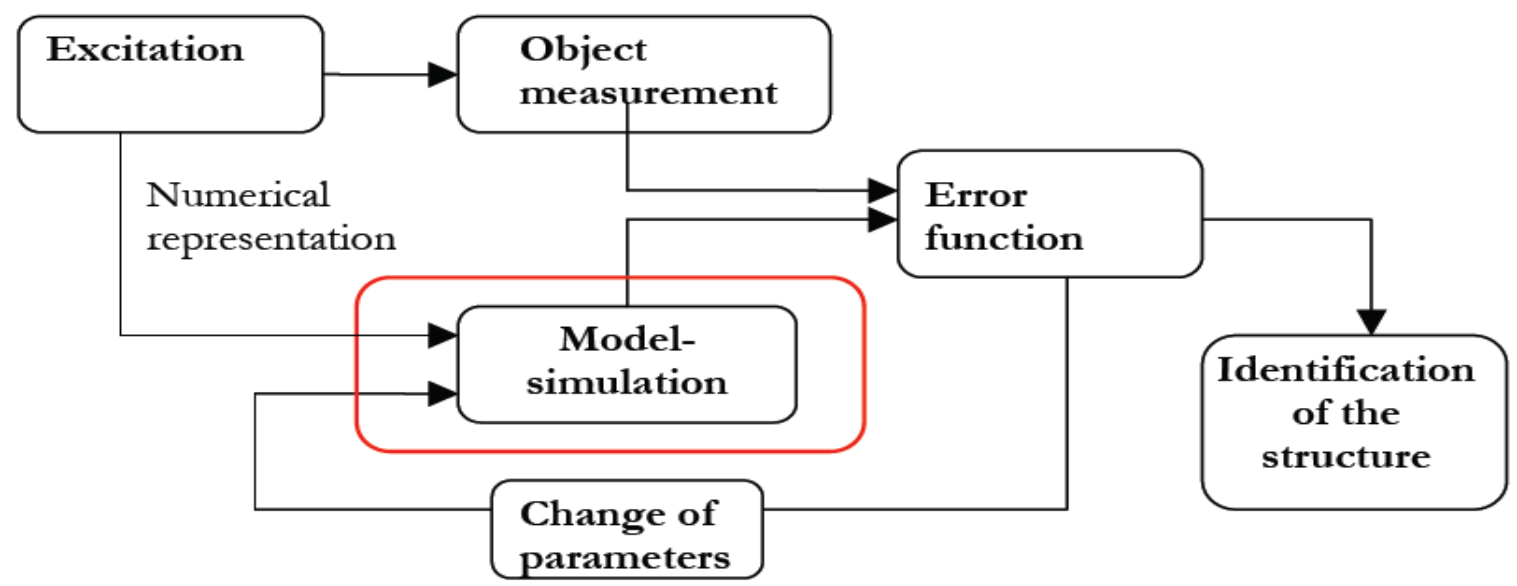

Fig. 1.. Thermal tomography algorithm 
The most important step in this procedure is to develop a realistic thermal numeric model of the tested object. Either geometry or values of thermal properties of this model have to be assumed. Also very important is to define conditions of measurement procedures, to allow proper registration of surface temperature distribution changes caused by application of controlled excitation. The next step is to perform simulation solving the forward problem, that means the calculation of the heat distribution within a given model induced by the external energy excitation. Then the simulation results are compared with measurement results and the error function is calculated. If an error value is greater than the established level, thermal parameters of the model or it's geometry are changed by the assumed function adjusting the sensitive parameters. In the case when the error value is below the agreed level, model parameters are accepted as the solution, giving 3-D structure with known thermal properties.

\section{Model and phantom}

To perform reliable analysis of the problem several physical phantoms and their numerical models have been worked up. Here two phantom models of different geometry and different thermal properties are discussed. The first gelatine phantom was made with inserted cubic copper defects placed at different depths. The total thickness of the phantom was 3.5 $\mathrm{cm}$; four defects were inserted at the depths $2 \mathrm{~mm}, 5 \mathrm{~mm}, 10 \mathrm{~mm}$ and $20 \mathrm{~mm}$. Thickness of these defects was, respectively: $22 \mathrm{~mm}, 20 \mathrm{~mm}, 15 \mathrm{~mm}$ and $5 \mathrm{~mm}$; all of the surface $1 \mathrm{~cm} \times 2 \mathrm{~cm}$. The numerical model and the real phantom are shown on Fig. 2.



bl

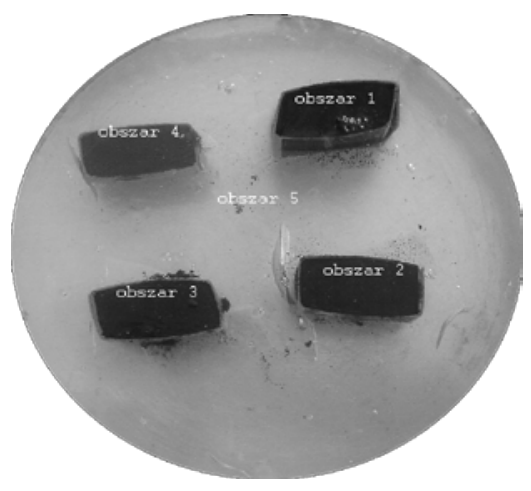

Fig. 2. Gelatine phantom with cooper defects; a/ the numerical model and b/ the gel phantom

The second phantom was made as a pile of several layers of the material Fe4; $10 \mathrm{~mm}$ total thickness with six holes of varying cross-section and depth. The first three holes with the diameter respectively 3,5 and $7 \mathrm{~mm}$ were placed at the depth of $2 \mathrm{~mm}$. The thickness of holes was $6 \mathrm{~mm}$. The next three holes with the diameter of $5 \mathrm{~mm}$ were placed at the depths 2,4 , and $6 \mathrm{~mm}$. The numerical model and the real phantom are shown on Fig. 3.
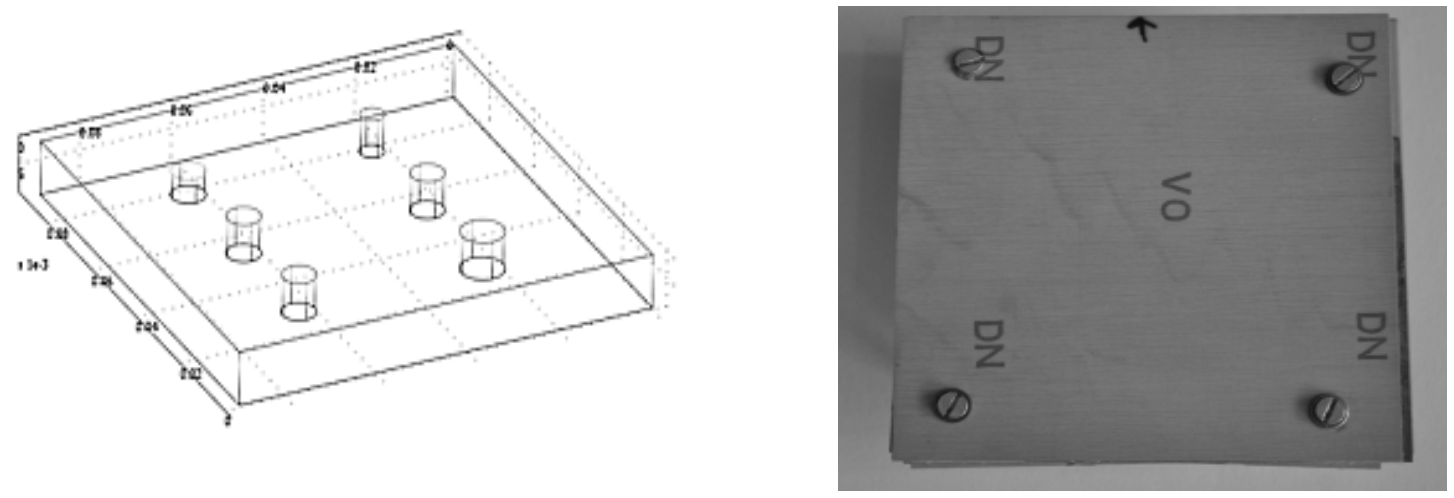

Fig. 3. Fe4 phantom with air whole defects: simulation model - on the left, real phantom - on the right 


\section{Simulation}

In order to assess the possibility of reconstructing tested object parameters using cold excitation the simulation studies were performed. A solution of the forward problem in material structures requires solving of the heat conduction equation $[7,8,9]$ of a tested 3D structure. The basic equation describing heat conduction is of the parabolic type:

$$
\operatorname{div}(k \cdot \operatorname{grad} T)-c_{w} \rho \frac{\partial T}{\partial t}=-q(P, t) .
$$

where $T$ - temperature $[\mathrm{K}] ; k$ - thermal conductivity $[\mathrm{W} /(\mathrm{m} \cdot \mathrm{K})] ; c_{w}$ - specific heat $[\mathrm{J} /(\mathrm{kg} \cdot \mathrm{K})] ; \rho-\operatorname{density}\left[\mathrm{kg} \cdot \mathrm{m}^{-3}\right], t-t^{-3} \mathrm{me}[\mathrm{s}]$, $q(P, t)$ - spatial density of the power generated or dissipated [W $\left.\mathrm{m}^{-3}\right]$.

This equation enables to calculate thermal response of a tested object after external excitation. For the simulations it was assumed that the geometry and thermal properties of the tested object, the temperature distribution at $t=0 \mathrm{~s}$ and excitation parameters are known. In the steady state the constant temperature inside the object equal to $20^{\circ} \mathrm{C}$ was assumed. For the simulation the two models defined above were accepted. The external excitation was simulated as a forced convection heat exchange with following parameters: convective heat transfer coefficient $=100\left[\mathrm{~W} \cdot \mathrm{m}^{-2} \mathrm{C}^{-1}\right]$, temperature of a fluid $-10^{\circ} \mathrm{C}$ (values of parameters similar to $\mathrm{CO}_{2}$ forced flow). The duration of stimulation was: $10 \mathrm{~s}, 20 \mathrm{~s}, 30 \mathrm{~s}, 60 \mathrm{~s}$ and $120 \mathrm{~s}$.

Changes in temperature on the surface of a tested object are dependent on the location and the size of structure disturbances. Based on this analysis measurement conditions and stimulation duration times for testing of real phantoms were chosen. This choice was made based on values of the thermal contrast $\mathrm{C}(\mathrm{t})$ [1]

$$
\mathrm{C}(\mathrm{t})=\mathrm{T}_{\text {def }}(\mathrm{t})-\mathrm{T}_{\text {no-def }}(\mathrm{t})
$$

where $T_{\text {def }}(t)$ - temperature at the centre of a defect; $T_{\text {no-def }}(t)$ - temperature of not affected area. For a detailed analysis the following parameters were defined: $C_{\max }$ - the maximum value of thermal contrast over a defect, $t_{c \max }-t_{\text {ime }}$ when maximum thermal contrast occurred ( time after which the area with the defect is most noticeable). These parameters were calculated for all the cases of the numerical model. The simulation results for Fe4 model are shown in Tab.1.

\begin{tabular}{|c|c|c|c|c|c|c|c|}
\hline configuration & defect & time of excitation[s] & 10 & 20 & 30 & 60 & 120 \\
\hline \multirow{2}{*}{1} & \multirow{2}{*}{$\begin{array}{c}\text { depth: } 2 \mathrm{~mm} \\
\text { thickness: } 6 \mathrm{~mm}\end{array}$} & $\mathbf{t}_{\mathrm{C} \max }[\mathrm{s}]$ & 37 & 43,5 & 51 & 77 & 136 \\
\hline & & $\mathrm{C}_{\max }\left[{ }^{\circ} \mathrm{C}\right]$ & 1,28 & 2,37 & 3,21 & 4,51 & 4,81 \\
\hline \multirow{2}{*}{2} & \multirow{2}{*}{$\begin{array}{c}\text { depth: } 2 \mathrm{~mm} \\
\text { thickness: } 2 \mathrm{~mm}\end{array}$} & $\mathbf{t}_{\mathrm{Cmax}}[\mathrm{s}]$ & 36,5 & 42,5 & 50 & 76 & 134 \\
\hline & & $\mathrm{C}_{\max }\left[{ }^{\circ} \mathrm{C}\right]$ & 1,28 & 2,36 & 3,18 & 4,4 & 4,53 \\
\hline \multirow{2}{*}{3} & \multirow{2}{*}{$\begin{array}{c}\text { depth: } 4 \mathrm{~mm} \\
\text { thickness: } 4 \mathrm{~mm}\end{array}$} & $\mathbf{t}_{\mathrm{Cmax}}[\mathrm{s}]$ & 85 & 89 & 93 & 108 & 163,5 \\
\hline & & $\mathrm{C}_{\max }\left[{ }^{\circ} \mathrm{C}\right]$ & 0,22 & 0,43 & 0,63 & 1,15 & 1,67 \\
\hline \multirow{2}{*}{4} & \multirow{2}{*}{$\begin{array}{c}\text { depth: } 4 \mathrm{~mm} \\
\text { thickness: } 2 \mathrm{~mm}\end{array}$} & $\mathbf{t}_{\mathrm{Cmax}}[\mathrm{s}]$ & 84,5 & 87 & 91 & 109 & 159 \\
\hline & & $\mathrm{C}_{\max }\left[{ }^{\circ} \mathrm{C}\right]$ & 0,22 & 0,43 & 0,63 & 1,1 & 1,56 \\
\hline \multirow{2}{*}{5} & \multirow{2}{*}{$\begin{array}{c}\text { depth: } 5 \mathrm{~mm} \\
\text { thickness: } 2 \mathrm{~mm}\end{array}$} & $\mathbf{t}_{\mathrm{Cmax}}[\mathrm{s}]$ & 118 & 118 & 122 & 136 & 178 \\
\hline & & $\mathrm{C}_{\max }\left[{ }^{\circ} \mathrm{C}\right]$ & 0,1 & 0,21 & 0,31 & 0,56 & 0,87 \\
\hline \multirow{2}{*}{6} & \multirow{2}{*}{$\begin{array}{c}\text { depth: } 6 \mathrm{~mm} \\
\text { thickness: } 2 \mathrm{~mm}\end{array}$} & $t_{c \max }[s]$ & 155 & 162 & 153 & 167 & 204 \\
\hline & & $\mathrm{C}_{\max }\left[{ }^{\circ} \mathrm{C}\right]$ & 0,05 & 0,11 & 0,16 & 0,3 & 0,5 \\
\hline
\end{tabular}

Table 1. Values of thermal contrast for the phantom material Fe4 with air defects

Table 1 summarizes these parameters calculated for an object made of Fe4 material for different durations of the cold excitation stream. The results show that for the excitation lasting only $10 \mathrm{~s}$ it was possible to recognize defects located at the depth of $2 \mathrm{~mm}$. However, it was impossible to identify the size of these defects, as evidenced by identical values of the thermal contrast. Use of the excitation lasting $60 \mathrm{~s}$ allow to differentiate defects located at the depth up to $6 \mathrm{~mm}$, but still it was impossible to determine the thickness of these defects. Only the simulation results performed for the excitation equal $120 \mathrm{~s}$ was allowing for a distinction of defects depth and their size. This was confirmed by the example of output temperature distribution simulation on the surface of the object after $80 \mathrm{~s}$ after the end of excitation. The character of temperature return to the steady state can be clearly seen in figure 4 . It depends on the properties of the inserted defect. 

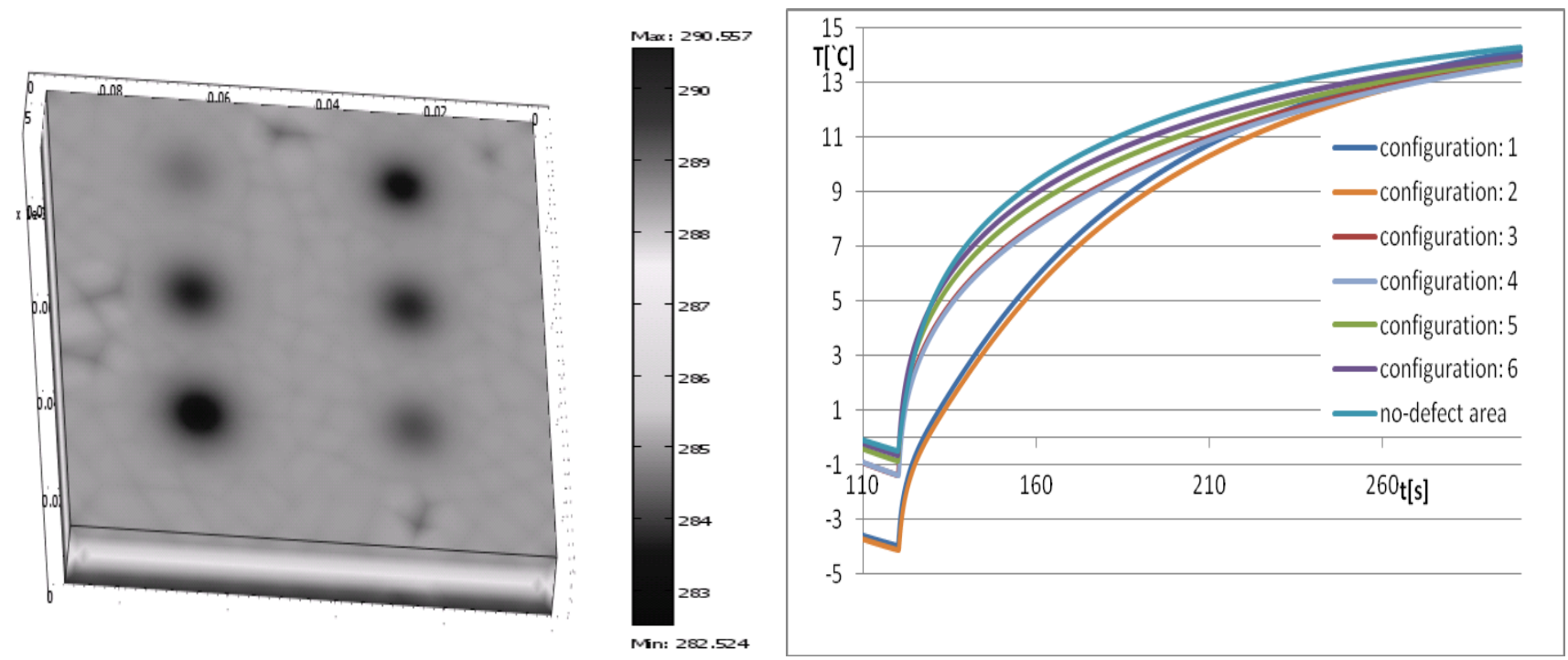

Fig. 4. Results of simulation

In table 2 the results of gelatine model simulations are presented. In this configuration it was practically impossible to determine defects that are deeper than $1.5 \mathrm{~cm}$ on the basis of temperature changes on the surface of the object. The maximum value of the thermal contrast for defect located at a the depth of $15 \mathrm{~mm}$ was 0.14 , the cooling time was equal to $200 \mathrm{~s}$. This level of thermal contrast does not allow to determine thermal parameters of object using thermal tomography method.

Table 2. Values of thermal contrast - material gelatine with cooper defects

\begin{tabular}{|c|c|c|c|c|c|c|c|c|}
\hline configuration & defect & $\begin{array}{c}\text { time of } \\
\text { excitation[s] }\end{array}$ & 10 & 20 & 30 & 60 & 120 & 200 \\
\hline \multirow{2}{*}{1} & \multirow{2}{*}{$\begin{array}{c}\text { depth: } 2 \mathrm{~mm} \\
\text { thickness: } 28 \mathrm{~mm}\end{array}$} & $\mathbf{t}_{\mathrm{Cmax}}[\mathbf{s}]$ & 30 & 36 & 45 & 80 & 145 & 234 \\
\hline & & $\mathrm{C}_{\max }\left[{ }^{\circ} \mathrm{C}\right]$ & 1,87 & 3,38 & 4,6 & 7,1 & 9,6 & 11 \\
\hline \multirow{2}{*}{2} & \multirow{2}{*}{$\begin{array}{l}\text { depth: } 5 \mathrm{~mm} \\
\text { thickness: } 25 \mathrm{~mm}\end{array}$} & $t_{C \max }[s]$ & 127 & 132 & 140 & 189 & 245 & 360 \\
\hline & & $\mathrm{C}_{\max }\left[{ }^{\circ} \mathrm{C}\right]$ & 0,51 & 0,98 & 1,4 & 2,5 & 4,2 & 5 \\
\hline \multirow{2}{*}{3} & \multirow{2}{*}{$\begin{array}{l}\text { depth: } 10 \mathrm{~mm} \\
\text { thickness: } 20 \mathrm{~mm}\end{array}$} & $\mathbf{t}_{\mathrm{Cmax}}[\mathbf{s}]$ & 300 & 300 & 300 & 300 & 300 & 395 \\
\hline & & $\mathrm{C}_{\max }\left[{ }^{\circ} \mathrm{C}\right]$ & 0,05 & 0,07 & 0,1 & 0,15 & 0,25 & 0,35 \\
\hline \multirow{2}{*}{4} & \multirow{2}{*}{$\begin{array}{l}\text { depth: } 15 \mathrm{~mm} \\
\text { thickness: } 15 \mathrm{~mm}\end{array}$} & $t_{c \max }[s]$ & 300 & 300 & 300 & 300 & 300 & 400 \\
\hline & & $\mathrm{C}_{\max }\left[{ }^{\circ} \mathrm{C}\right]$ & 0,01 & 0,02 & 0,03 & 0,05 & 0,07 & 0,14 \\
\hline
\end{tabular}

The results show that it was possible to reconstruct thermal parameters of the object based on comparison of measurement and simulation results. Using carbon dioxide cold excitation lasting $120 \mathrm{~s}$ or more It was possible to determine the defect size and a depth of defect placement up to about $15 \mathrm{~mm}$. Excitation lasting less than $120 \mathrm{~s}$ allows to specify the depth of a defect placement, but not it's size.

The discussed results allowed to plan ADT measurement conditions for analysis of properties of physical phantoms. As a source of energy stimulation a stream of carbon dioxide from the device to cryotherapy Cryo-T has been used. The experiment was carried out for different excitation times lasting: 10, 20, 30, 40, 60 and 120s. Distribution of temperature on the surface of a phantom has been registered for both, the cooling phase and the return to the steady-state temperature. For recording the infrared camera FLIR A320 was used with registration rate 6 frames per second. The measurement instrumentation set is shown in Fig. 5. 


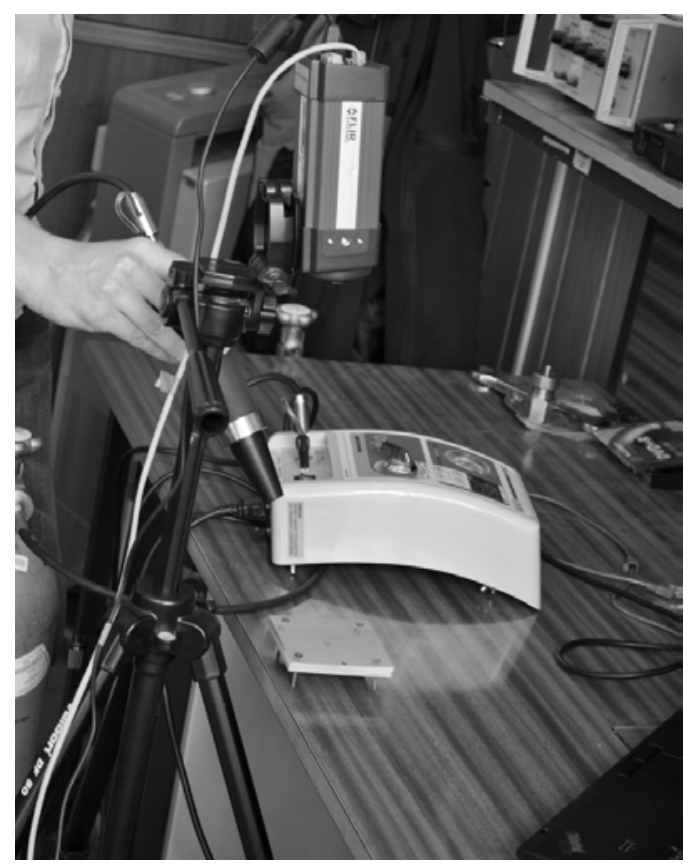

Fig. 5. Experimental set - from the bottom: the phantom, the cryotherapy excitation instrument and the IR-camera

\section{Reconstruction - thermal tomography algorithm}

The most desirable, but also the most general definition of the inverse problem in thermal tomography procedure allows to obtain full information about the structure and thermal properties of a tested object, e.g. spatial distribution of thermal conductivity and volumetric specific heat. This information is obtained based on the knowledge of the conditions of excitation, the initial state of a tested object and the thermal response recorded on the surface of the object as a result of the applied stimulation.

In the simplest case well-known is the total thickness of the reconstructed object, which is homogenous but the defect location, additionally thermal parameters of the bulk material and defects are also known. Unknown are locations and sizes of defects. The inverse problem solution procedure applied to the numerical model changes local thermal conductivity parameters in the model so that the forward problem solution converges to the measurement results. For this purpose, the objective function $\mathrm{F}$ for each pixel is calculated. The error is calculated for the phase after turning off the external excitation. The applied for calculations condition is minimization of the function:

$$
F(k)=\sum_{k=t}\left(T_{\text {mea }}^{k}-T_{\text {sym }}^{k}\right)^{2} .
$$

where $T_{\text {mea }}^{k}$ - measured temperature registered at the surface at time $\mathrm{k}$,

$T_{\text {sym }}^{k}$-simulated temperature at the surface at time $\mathrm{t}$.

Selection for the analysis only the phase of temperature return to a steady state was made due to the nature of excitation. The machine for cryotherapy was characterized by high inequality of stream of carbon dioxide which reaches the surface area of tested object. Changes in temperature recorded for a single pixel in the phase excitation are shown in Fig. 6 . Instability and the level of these changes makes it impossible to directly compare them to the simulation results. However, a factor that completely eliminated the cooling phase from the analysis was the impact of stream flow on the intrinsic value of the temperature which was registered by a thermographic camera. This flux causes the suppression of radiation that reaches the lens, which resulted in changing the registered temperature value by up to $2{ }^{`} \mathrm{C}$. From the standpoint of reconstruction procedure it was necessary to simulate the cooling of the surface to the temperature value that was recorded in the first moment after the termination of cooling, but the nature of these changes was not so important. The other problem was the uneven cooling of the surface of the object, in this context was necessary to use analytical method for measuring unsteady heat transfer coefficient. This coefficient was calculated by this procedure [10],[11],[12] independently for each pixel which resulted in the elimination of this problem. 


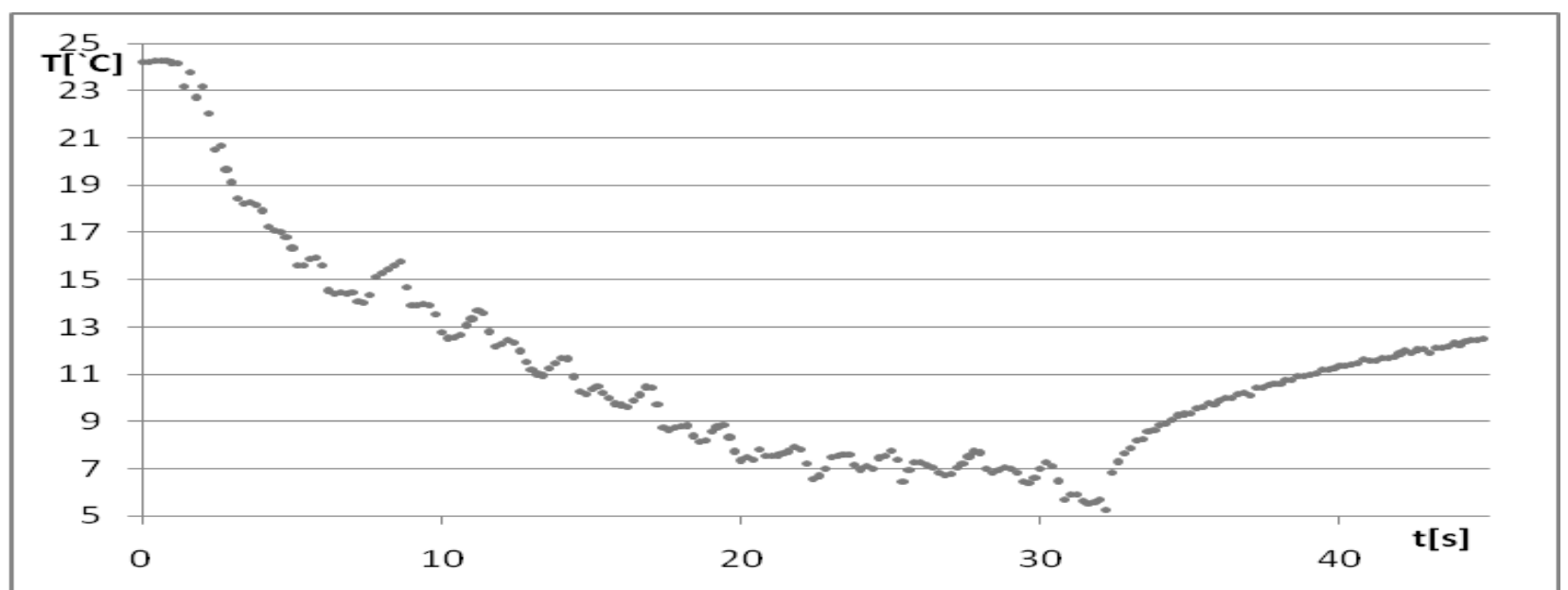

Fig. 6. Changes of single pixel temperature during the excitation phase, till $32 \mathrm{~s}$, followed by and natural recovery.

For the obtained results of measurements, reconstruction of thermal parameters according to the simplified procedure of reconstruction was carried out. We assumed that the object under examination consists of two materials of known thermal parameters (air and Fe-4) but the size and location of defects are unknown. Fig. 7 and Fig. 8 present the results of the reconstruction, which confirm that for such simplified assumptions, localization of defects by TT gives promising results. The results show the distribution of thermal conductivity at selected depths 2, 4 and $6 \mathrm{~mm}$. For Fig. 7 duration of cold excitation was 30s, while for the Fig. 8 the duration of stimulation was 120 seconds. For the both cases the defects (holes with different diameters, which were placed at the same depth) were successfully identified. Results of identification of the same diameter defects but placed at different depths were performed with little mistakes. The diameter of the defects that were reconstructed for the first case was less than in the prototype. While, for a longer period of excitation the reconstructed values were correct.

(A)

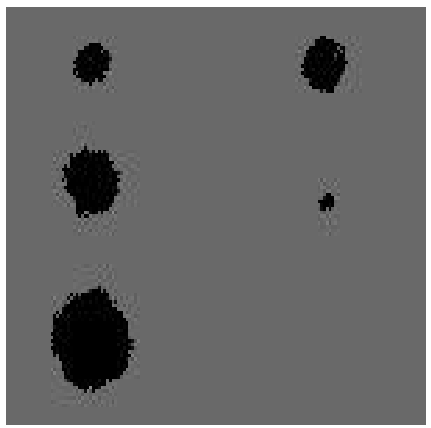

(B)

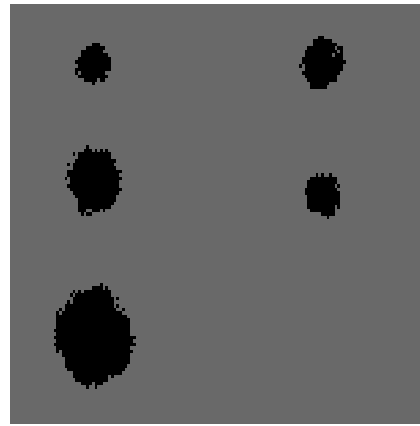

(C)

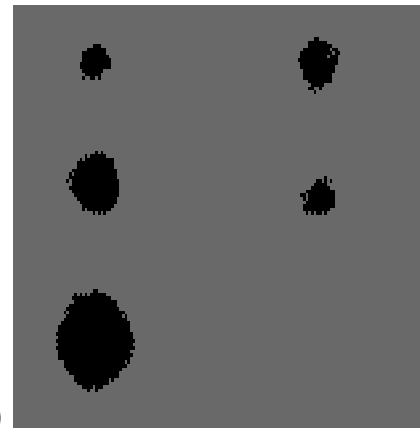

Fig. 7. The results of the reconstruction of phantom parameters: thermal conductivity at the depth $2 m m(A)$, $4 \mathrm{~mm}(B)$ and $6 \mathrm{~mm}(\mathrm{C})$ for the excitation lasting $30 \mathrm{~s}$.

(A)

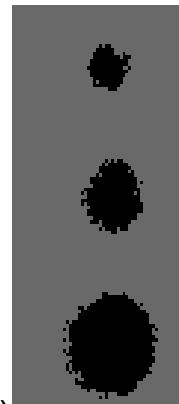

Fig. 8.
(C)

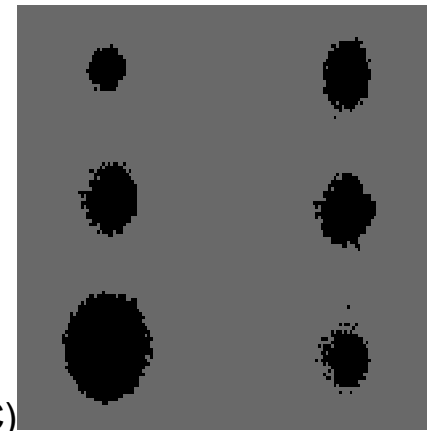

(B)
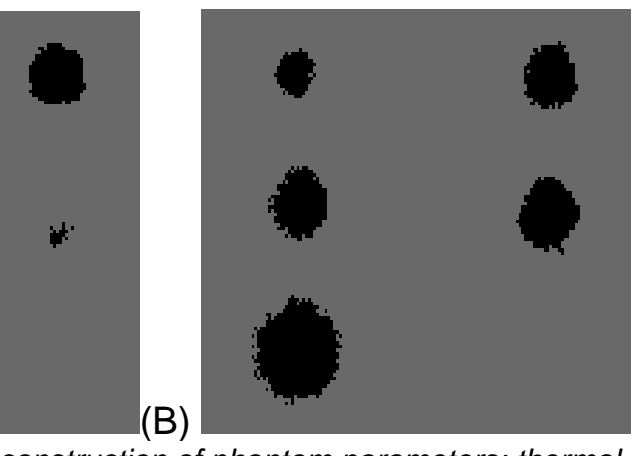

$4 \mathrm{~mm}(B)$ and $6 \mathrm{~mm}(\mathrm{C})$ for the excitation lasting $120 \mathrm{~s}$. 
However, in the case of no acceptance of such rigid assumptions concerning the knowledge of thermal parameters of the tested materials and excitation parameters, the algorithm did not provide clear results. The result of reconstruction presented in Fig. 9 shows how important is to determine appropriate terms of simulation, and especially the value of excitation. In this case, uniform value of carbon dioxide flux that reaches the surface was assumed. From the perspective of the simulation it meant adoption of identical value of the penetration coefficient for each pixel in the analyzed area. Determining the size and location of defects in this case was completely incorrect.

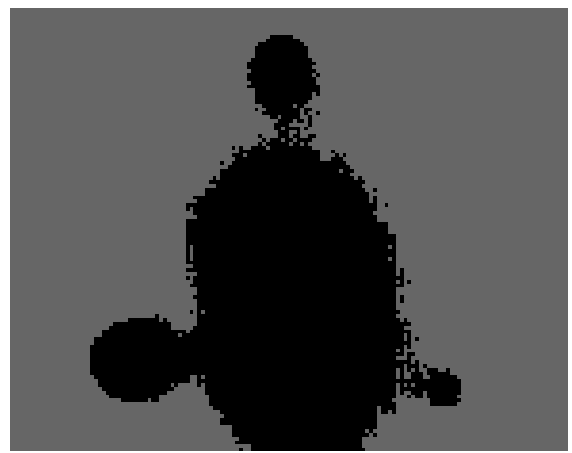

Fig. 9. Example of incorrect reconstruction of thermal conductivity at a depth of $2 \mathrm{~mm}$ caused by improper selection of excitation parameters.

According to the same procedure, reconstruction of thermal parameters for phantom of gelatin was performed. Identification was carried out for two cases, the duration of excitation lasting 30 and 120 seconds. Figure 10A presents the results of reconstruction of the first experiment. For areas where the depth of the defects was 2 and $5 \mathrm{~mm}$, reconstruction has been carried out very well. In those areas, a layer of copper was detected. By contrast, areas in which disturbances are located deeper than $5 \mathrm{~mm}$ were not identified. This confirms the simulation results obtained sooner which did not show significant changes in the value of thermal contrast for such a short time of excitation. On Fig. 10B reconstruction results for the second experiment are presented. In this case, the reconstruction was the most successful in areas with defects to 10 $\mathrm{mm}$ depth, in each case was correctly determined the presence of inclusions and the thickness of the first layer of gelatine. Inclusion located at a depth $15 \mathrm{~mm}$ as in the previous case was not detected. It follows from this that for this experimental conditions, copper layer which is located at a depth greater than $10 \mathrm{~mm}$ does not affect the temperature distribution on the surface of the phantom and therefore can not detect this disorder.

$32 \mathrm{~mm}$

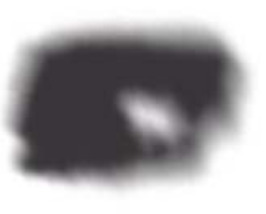

(A)
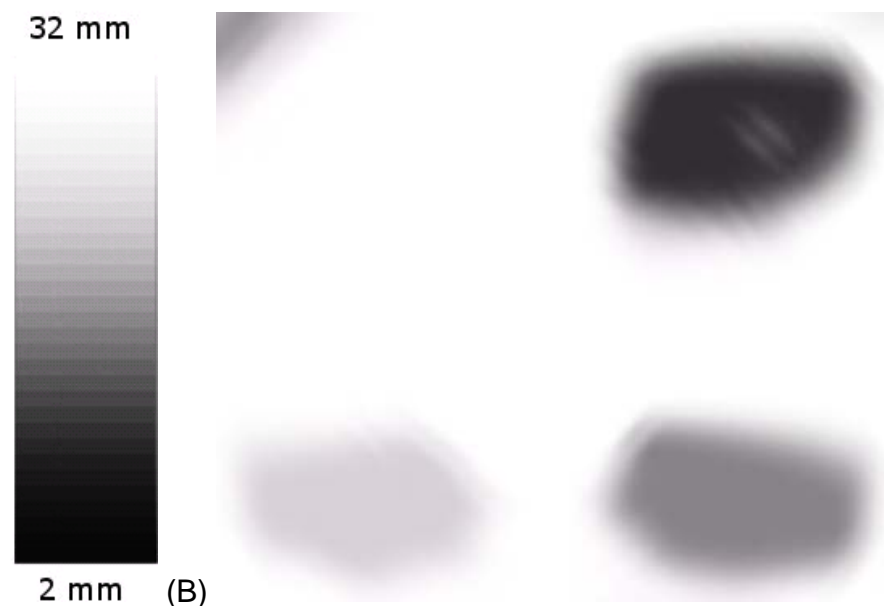

Fig. 10. The results of the reconstruction of phantom parameters - thickness of gelatine layer, $A$ - excitation time $30 \mathrm{~s}, \mathrm{~B}$ - excitation time 120s.

\section{Conclusions}

In this work possibilities of reconstructing object parameters using thermal tomography approach was analyzed. Use of forced stream of carbon dioxide as the excitation was positively investigated. Conducted numerical simulation and 
equivalent phantom measurements, showed that it was possible to identify defects localized to the depth of $15 \mathrm{~mm}$. A simplified definition of the inverse problem in the thermal tomography procedure, relying only on identification of location and size of thermal parameters disturbances (defects) shows promising results, too. This is confirmed by the results of reconstruction obtained for the two phantoms which were designed for physical measurements.

The quality of the reconstruction results may be improved while increasing duration of excitation, what is consistent with theoretical assumptions. The best results were obtained for the stimulation which lasted $120 \mathrm{~s}$. For such duration time of excitation it was possible not only to locate the defects, but also to differentiate their depth.

Change of properties of the excitation source may significantly affect the results of reconstruction. Improper choice of excitation parameters may ruin the process of simulation of the forward problem, causing incorrect result of the reconstruction of thermal parameters of objects.

The proposed approach to thermal tomography method gives promising results in the reconstruction of thermal parameters of the tested objects. Still it is necessary to further improve and optimize the procedures, especially to accelerate calculations of the reverse problem. applications.

Concluding - this method may find widespread application in non-destructive material testing but also in medical

Acknowledgement: This research was supported by the European Union in the framework of the European Social Fund the system project of the Pomorskie Voivodeship "InnoDoktorant" - Scholarships for PhD students, II edition.

\section{REFERENCES}

[1] Maldague X.P.V., "Theory and Practise of Infrared Technology for Nondestructive Testing", Wiley, New York, 2001.

[2] Vavilov V., Maldague X.P.V., Picard J., Thomas R.L, Favro L.D., "Dynamic thermal tomography - New NDE technique to reconstruct inner solids structure using multiple IR image processing", In: Review of progress in quantitative nondestructive evaluation. Vol. 11A; Proceedings of the 18th Annual Review, Brunswick(Germany), p. 425- 432., 1991.

[3] Vavilov V., Shiryaev V.V., Thermal Tomograph, USSR Patent \# 1266308, 1984 (in Russian).

[4] Maldague X.P.V., Cote J., Poussart D., Valvilov V., "Thermal Tomography for NDT of industrial materials", Canadian Society of Nondestructive Testing Journal pp. 22-32, May-Jun. 1992.

[5] Nowakowski A., in: "The Biomedical Engineering Handbook", Bronzino Ed. J.D., 3rd ed., Medical Devices and Systems, Vol. 22-1, CRC Taylor \& Francis, London, 2006.

[6] Nowakowski A., Kaczmarek M., Bajorek M., Moderhak M., Suchowirski M., "Advances of IR-Thermal Diagnostics in Medicine", in Diagnostics of Processes and Systems, Z. Kowalczuk, PWNT Gdańsk 2009.

[7] Bejan A.; "Heat Transfer" New York, Wiley.

[8] Carslow H.S., Jaeger T.S., "Conduction of Heat in Solids", Oxford Univ. Press London, 1959.

[9] Edwards A.L., "A Compilation of Thermal Property Data for Computer Heat-Conduction Calculations", UCLR50589, University of California Lewrence Radiation Laboratory, 1969

[10] Hirsh C., "Numerical Computation and External Flows" Vol I: Fundamentals of Numerical Discretization, New York, Wiley 1988.

[11] Anderson J.D., "Computational Fluid Dynamics. The Basics with Applications. New York, McGraw-Hill 1995.

[12] Luikov A.V., "Analitycal Heat Diffusion", Academic Press, N.Y \& London, 686, 1968 